\title{
The Present Situation and Quality Evaluation for Higher Education in China
}

\author{
Cuicui CUI, Songtao LI, Shulai ZHU, Ying XING* \\ Department of neurology, China-Japan Union Hospital of Jilin University, Changchun, 130033, China
}

*Corresponding Author

\begin{abstract}
Higher education quality is the core issue of education development in China. With the expansion of higher education, many practical problems also emerged. By this article, we analysize the present situation of higher education and quality evaluation in China, proposed the present stage which suited to the specific situation in our country in order to improve the quality of higher education with a new type of higher education quality evaluation system, which to establish a service-oriented education consciousness, the comprehensive talent and diversity of education quality and improve the sustainable development of national and the international competitiveness.
\end{abstract}

KEYWORD: higher education; evaluation; present situation

With the development of economy and the improvement of international status, higher education has gradually become a hot topic among all kinds of people. At the end of last century, the rapid expansion of higher education in our country and the increasing student numbers speed up the development trend of the popularization of higher education, which is beneficial to the direction of our country to cultivate more talents, comprehensively improve the quality of the national higher education, but high academic qualifications and low employment, high input and low output and talent surplus is still a realistic problem[1]. It is the common goal of scholars of the world to analyze the present situation of higher education, forecast the development trend of higher education, evaluate higher education quality in a reasonable way, and guarantee the quality of higher education when expanding the scale of higher education. In this article, , we try to seek effective ways or methods to improve and guarantee the quality of higher education through analyses the present situation of higher education.

\section{THE GENERAL OVERVIEW OF HIGHER EDUCATION QUALITY}

Higher education quality is the core issue of education development in our country, the embodiment of values education. The evaluation standard and the activities of higher education system are an momentous part of international competitiveness and national consciousness. Higher education quality is a multifaceted concept, scholars at home and abroad has not formed a consistent view[2], but we can understand the quality of higher education from the following aspects: from the view of national development, the quality of education can promote the development of society and economy, speed up the social progress. The point of view of talent training: knowledge, skills, quality on behalf of the personnel training level, security personnel quality, meet the needs of the society. From the macroscopic Angle, it refers to the higher education present situation, the development trend of economy and the harmony of culture; from the microcosmic point of view, it is the evaluation of educational philosophy, curriculum setting, teaching management system, environmental conditions, etc., and it is the embodiment of the present higher educational function.

Quality evaluation of higher education is a comprehensive analysis of the achievement [3] During the middle ages of western, scholars believed that as the first academic institutions, it mean higher learning , exploring knowledge, cultivating the humanistic principle of harmonious development, attaching great importance to the essence of education evaluation function, but it neglected the other functions of education. With the advent of the industrial revolution, this kind of higher education didn't have material value in the economic function of getting the attention of the 
society, with the development of economy, it aimed to cultivate talents needed for economic development and professional education development, its influence continues to this day. The quality standard is a development concept, its establishment is to solve the main problems and contradictions in accordance with the development of higher education, being era theme to think and establish the guidelines and principles of higher education quality standards, analyzed the advantage of education power and the differences between the education in our country, to promote and stimulate the development of the role of social progress; at the different levels of higher education, there are their own advantages and characteristics, the evaluation should avoid using only one standard to measure, in addition to general indexes such as the comprehensive development of innovative talent cultivation, universities should actively customize education idea, training target, etc[4].

\section{THE PRESENT SITUATION OF HIGHER EDUCATION IN CHINA}

During the decades of reforming and opening to the outside, Our country's higher education has been developing rapidly[5], from the aspects of management system and operational mechanism of great changes have taken place, The change from elite to mass higher education model of the stage is experiencing. Compared to previous elite higher education, it emphasized the importance of academic knowledge of limited market function which cannot meet the social demand for knowledge quantity, the wide scope of popularization of higher education is provided, big basement, comprehensive training, which develop in academic, technical, and characteristics such as ability, specialty, professional showing in every post that provided technical support to the social development. at the same time of keeping reserved elite higher education , another is to set up the key universities ,ordinary schools, colleges and vocational and technical, private schools, such as undergraduate, cultivate undergraduate, master, doctor and different levels of talent which can fully embody the hierarchy and popularization of education [6]. Although the popularization of higher education is developing rapidly, the base of students increased dramatically, imperfect education system and the evaluation system, excessive emphasis on the social function of the talent, and neglecting the cultivation of individual quality problems appear, all lead to higher education quality declining gradually.

\section{THE QUALITY EVALUATION OF HIGHER EDUCATION IN CHINA}

As the product of higher education, the students will eventually face the choice of the market, the purpose of the education quality evaluation emphasized not only on teaching process and the effect of internal and external characteristic, but also social and students of institutions of higher learning education and requirements [7]. Chinese higher education quality standards under the condition of planned economy have formed the "commonality, individuality", "heavy inspection, light social practice teaching itself" misconceptions. For the different types, different levels and personality characteristics of colleges and universities, single assessment standard is lack of hierarchy, it is unfair all kinds of colleges and universities are used to implement unified quality evaluation standards. Individual development is hampered by a certain degree. It is common that Chinese universities used it's own evaluation ways [8], for instance, it is lack of evaluation test and credibility, lack of external supervision if only based on student test scores, teachers' teaching level, hardware conditions, such as one-sided to measure the quality of education, compared with enrollment, students in out of the campus cannot increase of the actual level and practical ability.

\section{RELEVANT COUNTERMEASURES}

Under the new situation, it is an urgent need to establish a new type of higher education quality evaluation system to improve higher education quality evaluation of defects and shortcomings, we think to do these from the following several aspects [9-10].

\subsection{The establishment of a diversified evaluation system}

First, the diversification of the student source, expectations and the development of social demands determined the diversification of higher education quality standard and the social, people from all society should pay attention to the quality of higher education, variety of standard as the breakthrough point to make "university rankings" [11], although the science is not strong enough to fully reflect the diversity evaluation standard for the importance of higher education quality evaluation; Secondly, emphasizing the diversification of evaluation objects cannot leave the teaching quality of higher education or educational condition and so on to equal, it should also be the level of scientific research in colleges and universities and social benefits, higher education of the whole investment, education, 
comprehensive evaluation, such as "product" quality, at the same time the ideology of policy makers and managers should also be included, that is to say, mix education achievement, education process, education system and education evaluation itself quality evaluation together to form a comprehensive, specific and persuasive evaluation results. Finally diversified evaluation institutions, institutions of higher learning education quality evaluation should be subject to supervision by government, education agencies, social organizations and test, only different levels and types of institutions of higher learning with different quality standards, can guide its accurate positioning under different education quality standards and to seek development direction and space.

Highlight the importance of the social accountability in the evaluation of higher education quality.

Social accountability is the product of popularization of higher education, higher education in the period of elite culture, institutions of higher learning scale is small, several people have the opportunity to receive higher education, the role of social accountability is difficult to be known by the public. In recent 10 years, contrary to the slow way, our country's higher education development endure large scale rapid expansion, which form large, gradually perfect the system of education, it is relatively rare in the world. Students enrollment are rising, at the same time, profound changes have been in higher education, higher education and the social relationship with the change of the nature, education quality is closely related to millions of households, each year millions of graduates, including undergraduate, graduate and step to society, to the industry jobs, as a result the change of social relationships of higher education become the center of the "social", which influence the development of industry and progress. For a long time the higher education in China closed schools and relatively centralized administrative management mechanism, talents training target, teaching plan, teaching activities are centered on its own, such as education agencies, social public and community rarely touch teaching link. With the popularization of higher education, the social value of education is more outstanding, it have increased concerns about higher education, inquiry and supervision for colleges and universities respond to the social public legal rights, including the provision of comprehensive education, teaching information, release the quality report, and respond to the social from all over the world to the hot topic of higher education, such as government, the social public by active surveillance, proposed to establish a transparent and open relationship among universities, get rid of the passive position, more powerful in the improvement of the higher education system, improve the quality of education. A complete evaluation system just shown as below. (Figure 1, A complete evaluation system for Higher Education in China)

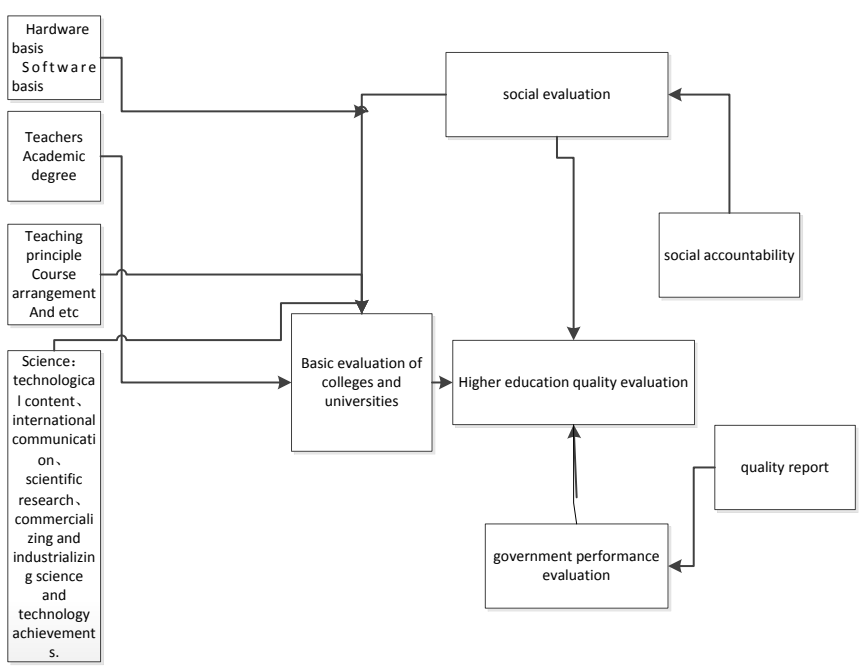

Figure 1. A complete evaluation system for Higher Education in China

\section{CONCLUSION}

In the context of economic globalization, our country should establish higher education power, set up a higher education system with international influence, which is representing the country's soft power. Today's higher education quality has not only confined to the university, but also more relate to the sustainable development of a country and international competitiveness. Higher education must continue to adhere to the people-oriented with the liberation and development of individual and perfect the fundamental starting point of the education activities, set up the humanist education values [12-13], one hand is to establish service consciousness of education, the other hand is the comprehensive talent and diversity of education quality, firmly establish the subject status of students in education and teaching, make it become the main body of learning, understanding of the main body, the development of the main body in order to the better development of our country's higher education and becoming an important part of international competitiveness.

\section{REFERENCES}

[1] Yan-jie Ye, Higher education quality, Journal of chongqing college of education, 2012, 25(1):118-120.

[2] Jin-yu Sun, Interpretation of the concept of higher education quality related and quality assurances, Economic and Social Development, 2007, (1):206-208.

[3] Bao-ying Fu, Higher education quality standard and value orientation and the dimensional analysis, Modern education science, 2005, 1: 20-22. 
[4] An-fu Zang, Min Jin Jia-lu Shi, Higher education quality and the level and the relevant conception. Higher education research , 2009, 30(11):13-18.

[5] Lu-xue Li, Higher education quality and new quality management thoughts. Journal of Shandong University, 2001, 2: 114-119.

[6] Bao-ge Zhang, A research of High school students quality evaluation system. Heilongjiang province higher education research, 2007, 12: 69-71.

[7] Ye-qing Duan, The knowledge system and higher education quality evaluation. Journal of nanchang institute of aviation industry, 2002, 4(3):96-99.

[8] Mei-sheng Qiu, The popularization of higher education quality research were reviewed. Jiangsu higher education. 2002, 1: 28-34
[9] Mao-zi Li, Several problems should be solved of Higher education quality in the social accountability. Journal of Gannan Teachers College, 2012(2):71-74.

[10]Lei Chen,Jing Xiao, The diversification of China's higher education quality. Teaching research, 2005, 28(2):96-98

[11]Jian-hua Hu, Value-outlook of higher education under the vision of higher education quality. Journal of Higher Education, 2005, 26(11):5-9.

[12]Zhi-feng Li, Kai-jie Yang, Jing Yi, etal, some basic problems of Higher education power development strategy in the quality and level. Higher Education Development and Evaluation, 2009, 25(5):97-105.

[13]Jian-hua Wang, Higher education quality researchmanagement point of view. Journal of Higher Education, 2009, 30(2):1-9. 